\title{
Long-term endoscopic submucosal dissection with postoperative lung injury: a case report
}

Qian-Mei Zhu' ${ }^{1,2}$, Hong Tu$^{1}$, Bing $\mathrm{Hu}^{3}$ and Xiao Wang ${ }^{1 *}$ (D)

\begin{abstract}
Background: Endoscopic submucosal dissection (ESD) has been recognized as a safe and minimally invasive technique for the removal of early gastric cancer. Here, we describe a case of extended-duration ESD for a gastric tumor associated with intraoperative perforation and bleeding. Unfortunately, the patient developed acute lung injury (ALI) after the operation.

Case presentation:: A 72-year-old woman received ESD for a gastric tumor under general anesthesia. Preoperatively, endoscopic ultrasonography (EUS) showed a $3.1 \times 3.5 \mathrm{~cm}$ hypoechoic, well-defined mass at the junction of the antrum and body of the stomach on the greater curvature, originating in the muscularis propria layer. During the ESD procedure, when the submucosal mass was stripped, it was found to be closely adhered to the muscular layer and serosa layer, and a full-thickness incision was performed. The abdominal cavity was gradually filled with carbon dioxide gas, and abdominal puncture was performed to reduce intra-abdominal hypertension (IAH). Because the mass adhered to the greater omentum and there was more bleeding during the operation, a long duration of hemostasis and suturing of the wound was required. The whole operation lasted nearly $9 \mathrm{~h}$, and total blood loss was 800 $\mathrm{ml}$. After surgery, acute lung injury was suspected, and the patient was sent to the intensive care unit (ICU) for further treatment.
\end{abstract}

Conclusions: The operation time of ESD and IAH caused by perforation are closely related to a poor prognosis. We should pay attention to the impact of operation time on patients and improve awareness regarding protecting important organ functions.

Keywords: ESD, ALI, Long-term, Perforation, Case report

\section{Background}

Endoscopic submucosal dissection (ESD) is a wellpracticed and safe minimally invasive technique for the removal of early cancers and large lesions from the luminal gastrointestinal tract [1]. However, perforation and

\footnotetext{
*Correspondence: 1490829116@qq.com

1 Present Address: Department of Anesthesiology, West China Hospital, Sichuan University \& The Research Units of West China (2018RU012), Chinese Academy of Medical Sciences, No. 37 Guoxuexiang, Wuhou District, Chengdu 610041, Sichuan, China

Full list of author information is available at the end of the article
}

bleeding are two major and serious ESD-related complications [2]. Studies have shown that when the diameter of gastric tumors is larger than $3 \mathrm{~cm}$, the intraoperative perforation rate can be as high as $12 \%$, and the bleeding rate can be as high as 6\% [3]. We report a case of an older woman who underwent a 9-h procedure due to bleeding and perforation during ESD for gastric tumor. Unfortunately, the patient developed acute lung injury (ALI) after the procedure. Informed consent for publication was obtained from the patient. 


\section{Case presentation}

A relatively healthy 72-year-old woman, weighing $49 \mathrm{~kg}$ and with a height of $143 \mathrm{~cm}$, received ESD for a gastric tumor under general anesthesia. She had only a history of hypertension and took medication regularly. Preoperative examinations, including white blood cell count, platelet count, coagulation system and electrocardiogram (ECG), were all normal. Endoscopic ultrasonography (EUS) showed a $3.1 \times 3.5 \mathrm{~cm}$ hypoechoic, well-defined mass at the junction of the antrum and body of the stomach on the greater curvature, originating in the muscularis propria layer. The pathology of biopsy specimens included a large number of red blood cells, a small number of spindle cells and proliferative epithelial cells, which did not rule out the possibility of neurogenic cells; severe chronic inflammation of the mucosa with a lymphoproliferative aspect was also detected. After discussion with the patient and her relatives, endoscopic resection was conducted, and written informed consent was obtained from the patient before the operation.

Before the procedure, the patient's vital signs were normal. Mechanical ventilation (volume controlled and $\mathrm{FiO}_{2}$ was $50 \%$ ) was performed after induction of general anesthesia; anesthesia was maintained with propofol and remifentanil. Based on gastroscopy, there was a protuberant lesion with a size of approximately $3.1 \times 3.5 \mathrm{~cm}$, with a central depression and soft touch (Fig. 1a). A lesion mass was seen after mucosal incision with a dual knife. When the submucosal mass was stripped, it was found to be closely adhered to the muscular layer and serosa layer, and a full-thickness incision was performed. The gastric perforation is shown in Fig. 1b. The abdominal cavity was gradually filled with carbon dioxide gas, and the peak airway pressure gradually increased to $30-35 \mathrm{~cm} \mathrm{H}_{2} \mathrm{O}$. Another surgeon performed abdominal puncture to reduce the high intra-abdominal pressure. The mass adhered to the greater omentum, and there was more bleeding during the operation. First, foreign body forceps and hot biopsy forceps were used for hemostasis. After the bleeding stopped, the lesion was completely removed. The wound was sutured with a titanium clip and nylon ring double-layer purse (Fig. 1c). The whole operation lasted nearly $9 \mathrm{~h}$, and total blood loss was $800 \mathrm{ml}$.

During recovery in the postanesthesia care unit (PACU), the patient was found to have a fast respiratory rate $(40-45 \mathrm{bpm})$ and low tidal volume (120-170 $\mathrm{ml}$ ), even after intravenous administration of neostigmine and atropine to recover breathing. $\mathrm{PetCO}_{2}$ was 45-55 mmHg and $\mathrm{SpO}_{2} 100 \%$. Venous blood gas analysis showed that the $\mathrm{pH}$ was 7.24 and $\mathrm{PCO}_{2} 64.3 \mathrm{mmHg}$. From lung auscultation, the breath sounds of both lungs were thick, and scattered moist rales were heard. Considering that the operation time was too long, long-term intra-abdominal hypertension (IAH) and mechanical ventilation had caused obvious damage to the patient's lung function, she was transferred to the intensive care unit (ICU) with an endotracheal tube for further improvement. Bedside chest X-ray on the day after surgery revealed scattered inflammation in the lung (Fig. 2a). The patient was diagnosed with pulmonary infection and acute respiratory distress syndrome (ARDS). Four days later, chest computed tomography (CT) still showed scattered inflammation in both lungs, especially in the lower lobes, and a small amount of pleural effusion was found on both sides (Fig. 2b). After 7 days of anti-inflammatory and gastric protective treatment in the ICU, the tracheal tube was removed, and the patient transferred back to the general ward on the 8 th day.
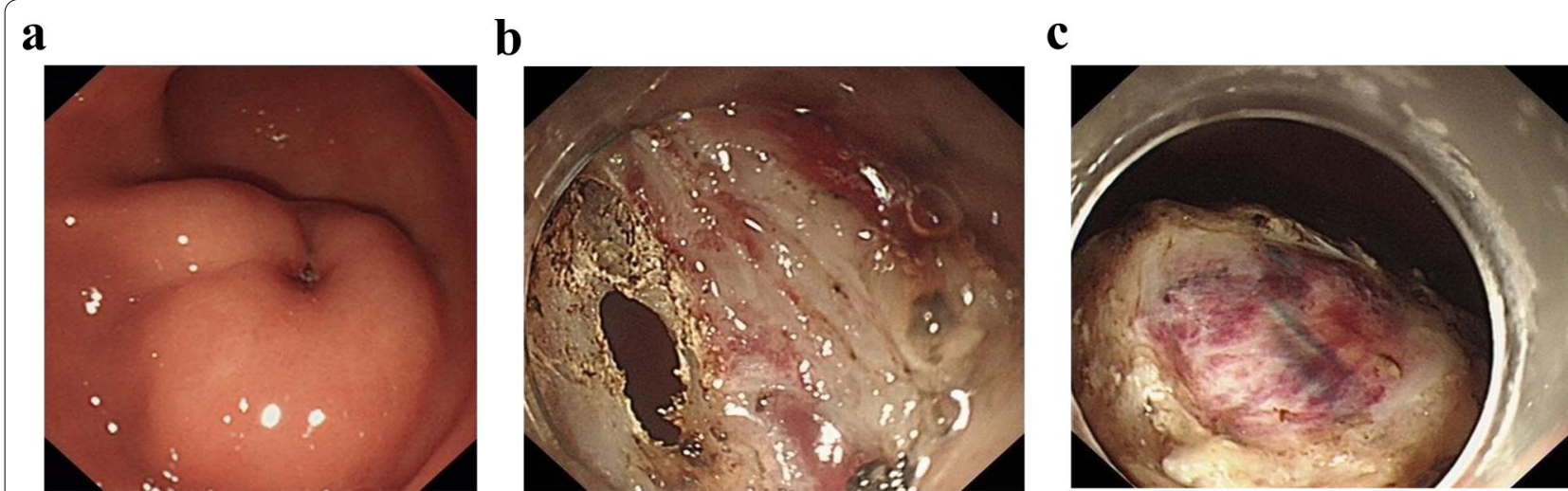

Fig. 1 Gastroscopy images in the surgery. a Before surgery, a $3.1 \times 3.5 \mathrm{~cm}$ hypoechoic mass at the junction of antrum and body of stomach was seen. The center of the tumor was sunken and tough. $\mathbf{b}$ Intraoperative perforation. $\mathbf{c}$ The perforation was sutured at the end of the surgery 

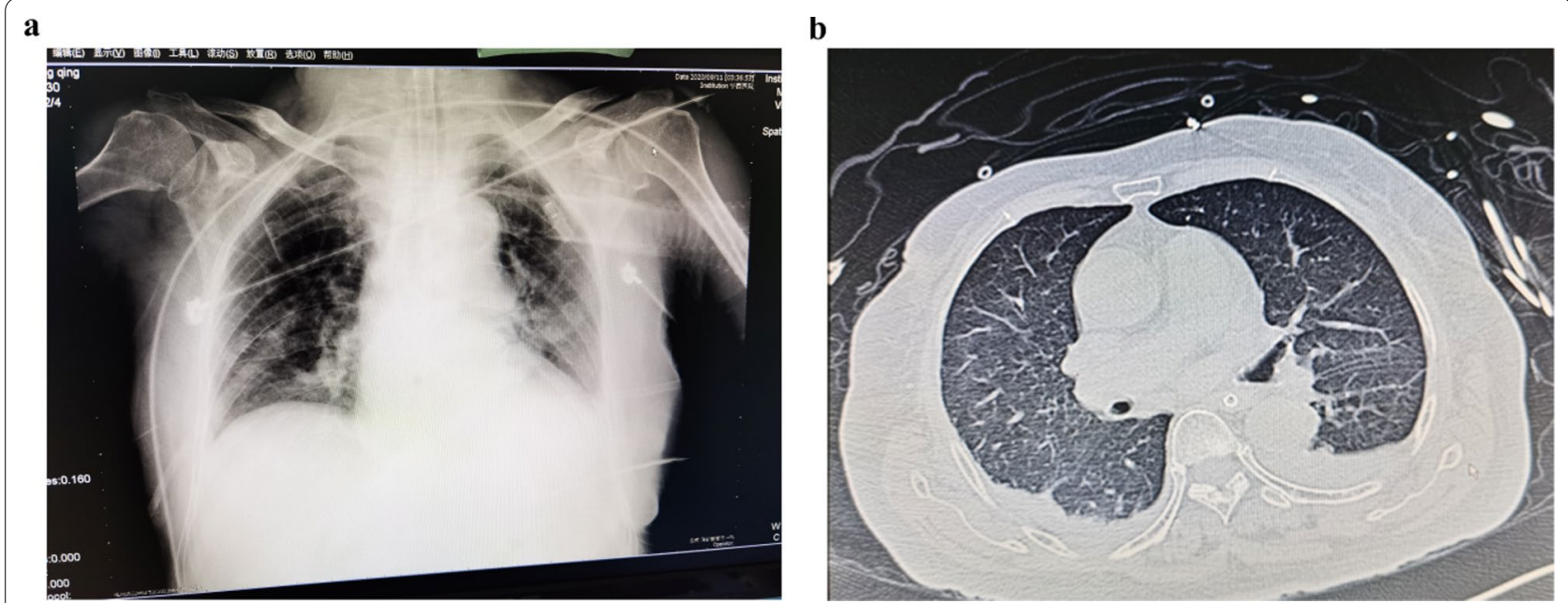

Fig. 2 Chest imaging examinations. a Chest X-ray on the day after surgery showed scattered inflammation in both lower lungs. b Computed tomography $(\mathrm{CT})$ on the 4th day after surgery demonstrated scattered inflammation in both lungs

\section{Discussion and conclusions}

It has been reported that most ESD procedure times are no more than $2 \mathrm{~h} \mathrm{[4]}$, and such long-duration ESD for gastric tumors has not been reported to date. There were unexpected difficulties during this procedure: as the mass had invaded the muscular layer and serosa layer, a fullthickness incision was necessary to completely cut off the tumor. In addition, endoscopic hemostasis and tumor stripping are more difficult and time-consuming than an open operation, which leads to such a long procedure time. Prolonged mechanical ventilation, IAH caused by gastric perforation and possible intraperitoneal infection resulted in obvious ALI and a prolonged postoperative hospital stay. Endoscopic surgery is difficult, and open surgery should be considered if the perforation cannot be closed in a timely manner.

Because endoscopic management can be equal to or even superior to conventional surgery in terms of longterm survival $[5,6]$, the number of patients undergoing ESD is increasing. It is undeniable that minimally invasive treatment is more likely with elderly patients. As the recently published guidelines describe [1], the absolute indications for ESD are "(i) nonulcerated, clinically intramucosal (cT1a), differentiated-type carcinomas with a long diameter $>2 \mathrm{~cm}$; (ii) ulcerated, cT1a differentiatedtype carcinomas with a long diameter $\leq 3 \mathrm{~cm}$; and (iii) nonulcerated, cT1a undifferentiated-type carcinomas with a long diameter $\leq 2 \mathrm{~cm}$ ". Expanded indications are defined as lesions that are presumed to have $\mathrm{a}<1 \%$ risk of lymph node metastasis. Relative indications are those who do not meet the requirements for absolute or expanded indications, or open surgery cannot be recommended when taking into account the patient's condition.
Cases with gastrointestinal tumors are prone to intraoperative or postoperative perforation if the tumor originates from the deep muscularis propria layer or the muscle layer is damaged during ESD treatment, which has been described in many reports [3, 7, 8]. Similarly, endoscopic treatment of diverticulum-associated intestinal tumors is challenging due to the lack of a muscle layer [9]. However, there are cases of esophageal schwannoma involving the muscle layer without serious complications after ESD treatment [10].

In general, progress in surgical and related anesthesia technology has a goal of meeting the needs of patients. Endoscopic minimally invasive technology for the treatment of early gastrointestinal cancer is also based on patient benefit. However, regardless of the surgical method selected, the operation time should be strictly controlled. An operation time $\leq 1 \mathrm{~h}$ was once recommended to reduce the risk of postoperative infection in retrograde intrarenal surgery [11]. Ziolkowski et al. also reported that burn surgery for more than $3 \mathrm{~h}$ will increase postoperative complications [12]. If it is expected that the operation is difficult and that the duration would be long, whether to change the operation mode should be considered by weighing the benefit to the patient. Although technology needs breakthroughs, surgeons must seriously consider the benefits of surgical decision-making for individual patients. Anesthesiologists should also make efforts to protect organs systems, especially the lung.

In addition to intraoperative perforation and a large amount of total blood loss, the manifestation of postoperative ALI was a major concern in this case. The patient had no history of acute pulmonary inflammation or any 
chronic pulmonary disease before surgery. However, signs of pulmonary infection appeared from auscultation, as confirmed by postoperative chest X-ray and CT. The incidence of postoperative pulmonary complications in patients receiving ESD under general anesthesia is very low when compared with conscious sedation $[13,14]$, and postoperative pneumonia is often associated with intraoperative reflux aspiration [15]. In this case, we considered that the main factors of her ALI included long-term mechanical ventilation, systemic inflammatory response caused by gastric perforation, long-term IAH and advanced age. The long-term increase in intra-abdominal pressure (IAP) leads to increased airway pressure, decreased lung compliance, decreased diaphragm activity, atelectasis and hypercapnia. On the other hand, IAH can lead to insufficient perfusion of organs and aggravate multiple organ injury [16]. Gastric perforation itself can cause leukocyte activation, chemotaxis, leukocyte adhesion and vascular instability, which may result in ARDS [17].

Herein, we present a case of a long-duration ESD procedure for treating early gastric cancer. Based on this case, we realize that the operation time for ESD and IAH caused by abdominal organ perforation were closely related to the poor prognosis of patients. This case does not refute the advantages of ESD in benefiting patients; however, when treating patients with different conditions, the decision-making ability of endoscopists and anesthesiologists should be strengthened to reduce the incidence of postoperative complications.

\section{Abbreviations}

ESD: Endoscopic submucosal dissection; ALI: Acute lung injury; EUS: Endoscopic ultrasonography; ECG: Electrocardiogram; PACU: Post anesthesia care unit; CT: Computed tomography; IAH: Intra-abdominal hypertension; ICU: Intensive care unit; $\mathrm{SpO}_{2}$ : Pulse oxygen saturation; ARDS: Acute respiratory distress syndrome; IAP: Intra-abdominal pressure.

\section{Acknowledgements}

Not applicable.

\section{Authors' contributions}

QMZ was the major contributor in writing the manuscript. HT helped collect patient information. XW and $\mathrm{BH}$ were involved in the care of the patient. All authors read and approved the final manuscript.

\section{Funding}

Not applicable.

\section{Availability of data and materials}

Not applicable.

\section{Declarations}

Ethics approval and consent to participate

We gained the written informed consent of the patient to use her clinical information and photographic material for the publication.

\section{Consent for publication}

Written informed consent to participate and for publication was obtained from the patient. The signed informed consent form is available to the Editor upon request.

\section{Competing interests}

The authors declare no competing interests.

\section{Author details}

${ }^{1}$ Present Address: Department of Anesthesiology, West China Hospital, Sichuan University \& The Research Units of West China (2018RU012), Chinese Academy of Medical Sciences, No. 37 Guoxuexiang, Wuhou District, Chengdu 610041, Sichuan, China. ${ }^{2}$ Department of Anesthesiology, National Cancer Center/National Clinical Research Center for Cancer/Cancer Hospital, Chinese Academy of Medical Sciences and Peking Union Medical College, No. 17 Panjiayuan Nanli, Chaoyang District, 100021 Beijing, China. ${ }^{3}$ Department of Gastroenterology, West China Hospital, Sichuan University \& The Research Units of West China (2018RU012), Chinese Academy of Medical Sciences, No. 37 Guoxuexiang, Wuhou District, 610041 Chengdu, Sichuan, China.

Received: 20 May 2021 Accepted: 18 December 2021

Published online: 27 December 2021

\section{References}

1. Draganov PV, Wang AY, Othman MO, Fukami N. AGA institute clinical practice update: endoscopic submucosal dissection in the United States. Clin Gastroenterol Hepatol. 2019;17(1):16-25.e11. https://doi.org/10. 1016/j.cgh.2018.07.041.

2. Ono H, Yao K, Fujishiro M, Oda I, Uedo N, Nimura S, Yahagi N, lishi H, Oka $M$, Ajioka Y, et al. Guidelines for endoscopic submucosal dissection and endoscopic mucosal resection for early gastric cancer (second edition). Dig Endosc. 2021;33(1):4-20. https://doi.org/10.1111/den.13883.

3. Chen Q, Yu M, Lei Y, Zhong C, Liu Z, Zhou X, Li G, Zhou X, Chen Y. Efficacy and safety of endoscopic submucosal dissection for large gastric stromal tumors. Clin Res Hepatol Gastroenterol. 2020;44(1):90-100. https://doi. org/10.1016/j.clinre.2019.03.004

4. Ahn JY, Choi KD, Choi JY, Kim MY, Lee JH, Choi KS, Kim DH, Song HJ, Lee $\mathrm{GH}$, Jung $\mathrm{HY}$, et al. Procedure time of endoscopic submucosal dissection according to the size and location of early gastric cancers: analysis of 916 dissections performed by 4 experts. Gastrointest Endosc. 2011;73(5):9116. https://doi.org/10.1016/j.gie.2010.11.046.

5. Hasuike N, Ono H, Boku N, Mizusawa J, Takizawa K, Fukuda H, Oda I, Doyama H, Kaneko K, Hori S, et al. A non-randomized confirmatory trial of an expanded indication for endoscopic submucosal dissection for intestinal-type gastric cancer (CT1a): the Japan Clinical Oncology Group study (JCOG0607). Gastric Cancer. 2018;21(1):114-23. https://doi.org/10. 1007/s10120-017-0704-y.

6. Takizawa K, Ono H, Hasuike N, Takashima A, Minashi K, Boku N, Kushima R, Katayama H, Ogawa G, Fukuda H, et al. A nonrandomized, single-arm confirmatory trial of expanded endoscopic submucosal dissection indication for undifferentiated early gastric cancer: Japan Clinical Oncology Group study (JCOG1009/1010). Gastric Cancer. 2021;24(2):479-91. https://doi.org/10.1007/s10120-020-01134-9.

7. Zhou GY, Hu JL, Wang S, Ge N, Liu X, Wang GX, Sun SY, Guo JT. Delayed perforation after endoscopic resection of a colonic laterally spreading tumor: a case report and literature review. World J Clin Cases. 2020;8(16):3608-15. https://doi.org/10.12998/wjcc.v8.116.3608.

8. Bang CS, Baik GH, Shin IS, Suk KT, Yoon JH, Kim DJ. Endoscopic submucosal dissection of gastric subepithelial tumors: a systematic review and meta-analysis. Korean J Intern Med. 2016;31(5):860-71. https://doi.org/10. 3904/kjim.2015.093.

9. Hawa F, Al Hillan A, Catanzaro AT, Tworek JA, Gunaratnam NT. Endoscopic management of a tubulovillous adenoma within a diverticulum: report of a case and review of literature. Cureus. 2020;12(6):e8668. https://doi.org/ 10.7759/cureus.8668.

10. Li B, Wang X, Zou WL, Yu SX, Chen Y, Xu HW. Endoscopic resection of benign esophageal schwannoma: Three case reports and review of literature. World J Clin Cases. 2020;8(22):5690-700. https://doi.org/10.12998/ wjcc.v8.i22.5690. 
11. Zhang H, Jiang T, Gao R, Chen Q, Chen W, Liu C, Mao H. Risk factors of infectious complications after retrograde intrarenal surgery: a retrospective clinical analysis. J Int Med Res. 2020;48(9):300060520956833. https:// doi.org/10.1177/0300060520956833.

12. Ziolkowski N, Rogers AD, Xiong W, Hong B, Patel S, Trull B, Jeschke MG. The impact of operative time and hypothermia in acute burn surgery. Burns. 2017;43(8):1673-81. https://doi.org/10.1016/j.burns.2017.10.001.

13. Kim SH, Choi YS, Lee SK, Oh H, Choi SH. Comparison of general anesthesia and conscious sedation in procedure-related complications during esophageal endoscopic submucosal dissection. Surg Endosc. 2020;34(8):3560-6. https://doi.org/10.1007/s00464-020-07663-9.

14. Yamashita K, Shiwaku H, Ohmiya T, Shimaoka H, Okada H, Nakashima R, Beppu R, Kato D, Sasaki T, Hoshino S, et al. Efficacy and safety of endoscopic submucosal dissection under general anesthesia. World J Gastrointest Endosc. 2016;8(13):466-71. https://doi.org/10.4253/wjge.v8. ¡13.466.

15. Miyazawa M, Shimakawa T, Asaka S, Yamaguchi K, Murayama M, Usui T, Yokomizo H, Shiozawa S, Katsube T, Naritaka Y. Simultaneous Endoscopic Resection of Superficial Cancers of the Hypopharynx and Esophagus: A Case Report. J Nippon Med Sch. 2020;87(5):294-8. https://doi.org/10. 1272/jnms.JNMS.2020_87-509.

16. Sadeghi M, Kiani A, Sheikhy K, Taghavi K, Farrokhpour M, Abedini A. Abdominal compartment syndrome in critically III patients. Open Access Maced J Med Sci. 2019;7(7):1097-102. https://doi.org/10.3889/oamjms. 2019.228.

17. Bhatia M, Moochhala S. Role of inflammatory mediators in the pathophysiology of acute respiratory distress syndrome. J Pathol. 2004;202(2):145-56. https://doi.org/10.1002/path.1491.

\section{Publisher's Note}

Springer Nature remains neutral with regard to jurisdictional claims in published maps and institutional affiliations.

- fast, convenient online submission

- thorough peer review by experienced researchers in your field

- rapid publication on acceptance

- support for research data, including large and complex data types

- gold Open Access which fosters wider collaboration and increased citations

- maximum visibility for your research: over $100 \mathrm{M}$ website views per year

At BMC, research is always in progress.

Learn more biomedcentral.com/submissions 